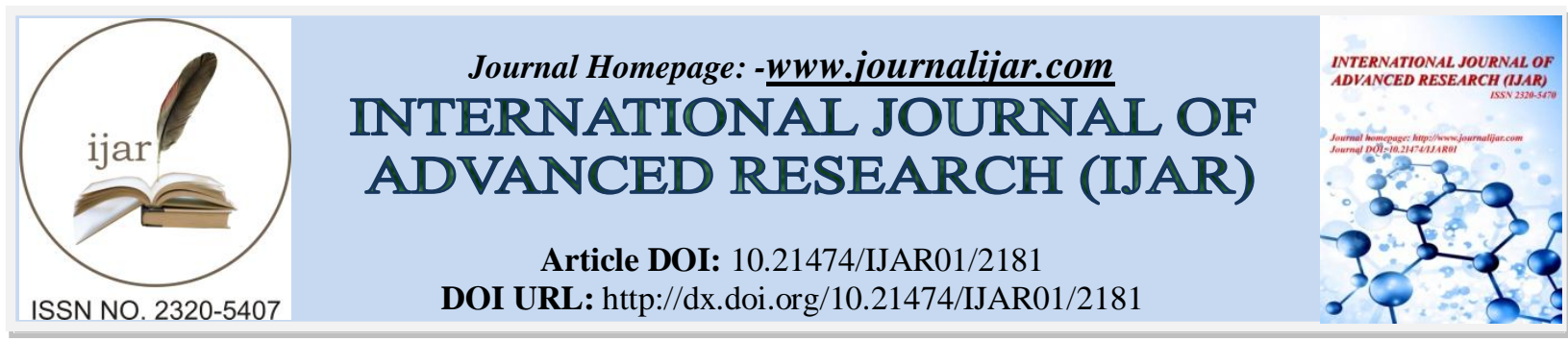

RESEARCH ARTICLE

\title{
STUDY OF ALTERNATIVE WILMS TUMOR GENE EXPRESSION IN ACUTE MYELOID LEUKEMIA.
}

\section{Magdy Mamdouh El Bordiny ${ }^{1}$, Ashraf Hussien Al-Ghandour ${ }^{2}$, Reham Abdel Haleem Abo Elwafa ${ }^{3}$ and Omneya Mohamed Kamal Fayed ${ }^{4}$.}

1. Professor in Clinical Pathology Department, Faculty of Medicine, Alexandria University, Alexandria, Egypt.

2. Professor in Internal Medicine Department, Faculty of Medicine, Alexandria University, Alexandria, Egypt.

3. Lecturer in Clinical Pathology Department, Faculty of medicine, Alexandria University, Alexandria, Egypt.

4. Specialist in, Alexandria University Hospitals, Alexandria, Egypt.

\section{Manuscript Info}

[.........................

Manuscript History

Received: 26 September 2016

Final Accepted: 29 October 2016

Published: November 2016

Key words:-

WT1, AML.

\section{Abstract}

Background:Wilms tumor 1 (WT1) is over-expressed in numerous cancers with respect to normal cells, and haseither a tumor suppressor or oncogenic role depending on cellular context. This gene is associated with numerous alternatively spliced transcripts, which initiate from two different unique first exons within the WT1 and the alternative (A)WT1promoter intervals.

Objective: We studied the AWT1 gene expression profile and its relation with other clinicopathological features in AML.

Methods: The level of AWT1 expression was assessed in 40 newly diagnosed AML patients and 40 healthy subjects as a control group usingRQ- PCR.

Results:AWT1 expression level was significantly higher in the AML patients in comparisonto the control group $(\mathrm{p}<0.01)$.

Copy Right, IJAR, 2016,. All rights reserved.

\section{Introduction:-}

Acute myeloid leukemia (AML) is defined as a cytogenetically and molecularly heterogeneous disease characterized by clonal proliferation of myeloid precursors with maturation arrest of myeloid cells in the bone marrow and impaired production of normal blood cells ${ }^{.(1,2)}$

It is considered the most frequent hematological malignancy in adults, with an estimated worldwide annual incidence of three to four cases/100,000 ${ }^{(3)}$ And in Egypt it was estimated for 2015 to be 1176 cases and expected this number to increase to 1323 by the year $2020 .^{(4)}$

Despite intensive research for new therapies and prognostic markers, it is still a disease with a highly variable prognosis among patients and a high mortality rate. ${ }^{(3)}$

Overexpression of the Wilmstumor 1 gene (WT1) is implicated in the prognosis of leukemia with high expression predicting disease progression in AML, as well as being intensively studied as a potential molecular marker for minimal residual disease(MRD) and treatment response. ${ }^{(5)}$

The Wilms tumor gene 1 (WT1) encodes a multifunctional protein important for regulation of cell growth and survival. It plays a role in many physiological developmental processes and also in cancers including leukemia.

Corresponding Author:- Magdy Mamdouh El Bordiny.

Address:- Professor in Clinical Pathology Department, Faculty of Medicine, Alexandria University, 
Although the oncogenic behavior of WT1 in leukemia has been proved, the mechanism has not yet been clearly explained.

In humans, the WT1 gene is located on chromosome $11 \mathrm{p} 13$ and consists of 10 exons. Many different isoforms exits for WT1, and it is estimated that it can have over 36 different isoforms generated by alternative transcription initiation, mRNA splicing and alternative translation initiation. ${ }^{(6)}$

Recently an alternative promoter incorporating a unique first exon has been described. The alternative WT1 transcript (AWT1) encodes a $32 \mathrm{kDa}$ protein deficient for the first 147 amino acids of the N-terminal of the WT1 protein, which lacks the repressor domain and the RNA recognition motif of the full-length protein. ${ }^{(7,8)}$.

The Wilms' tumor gene 1 (WT1) was first reported as a tumor suppressor gene in Wilms' tumor. However, later studies have shown the oncogenic properties of WT1 in a variety of tumors. It was recently proposed that WT1and its isoforms are chameleon genes, due to its dual functions in tumorgenesis. ${ }^{(9,10)}$. This may be used as a potential molecular marker for diagnosis, monitoring the clinical progress, the response to treatment, as well as a target for the development of novel therapeutic approaches. ${ }^{(11,12)}$

\section{Subjects and methods:-}

The present study was conducted in Clinical Pathology Department Faculty of Medicine, Alexandria University, Egypt. Informed consent was obtained from patients and controls according to the Ethical Committee for Human Research in the Alexandria UniversityHospitals.

Samples were collected from forty patients with newly diagnosed AML aged from 25 to 78 years admitted to the Department of hematology, Elmiry Hospital between August 2015 And June 2016.The diagnosis was made by standard morphological analysis and flow cytometryon BM/PB samples at diagnosis. Forty healthy subjects with matched age and sex and with no knownmalignancy were used as control group.

The aim of the present work is to assess the expression pattern of alternative AWT1 gene and to determine if this expression profile has correlation with age, sex.haemoglobin level,WBCs count ,blast countand AML subtypes.

Expression Detection: Total RNA isolationwas carried out by QIAampRNA Blood Mini Kit (QIAGEN, Germany, Cat No.52304) according to the manufacturer's instructions. The concentration and purity of RNA were measured

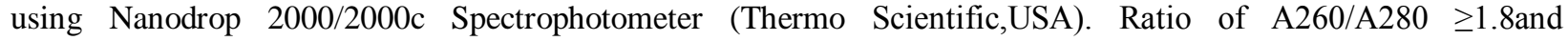
A260/A230 $\geq 1.8$ indicatedhighly pure RNA.Extracted RNA was reverse transcribed into complementary DNA (cDNA) by the High CapacitycDNA Reverse Transcription Kit. The primers sequencewas (Forward 5'TAGGAAGGT-GTTAGAAGGTTG) (Reverse5'CCCTA-AAACATAATTAAACC).Real time PCR was performed using roche Light Cycler 2.0 RealTime Cycler PCR system. The reaction was performed in $20 \mu 1$ reaction mixtureincluded $2 \mu \mathrm{l}$ RT product, $2 \mu \mathrm{l}$ of primers, $4 \mu \mathrm{l}$ ofrocheSyber green Master Mix and $7 \mu$ lnuclease free water. Reactions were incubated at $95^{\circ} \mathrm{C}$ for 10 minsfollowed by 45 cycles of $95^{\circ} \mathrm{C}$ for $10 \mathrm{~s}, 60^{\circ} \mathrm{C}$ for $15 \mathrm{~s}$ and $72 \mathrm{oC}$ for $25 \mathrm{~s}$. Beta actin was used as endogenous reference for normalizing the expression levels of AWT1 gene.

The relative quantification of AWT1 was calculated using the comparative CTmethod $\left(2^{-\Delta \Delta C t}\right)$.

\section{Results:-}

The Subjectscharacteristicswere summarized in table (1).

Detection of degree of expression of AWT1 in cases and controls: Regarding the level of AWT1expression at initial diagnosis we found that it was significantly overexpressed in AML patients relative to control group With a median of 5.54 in AML cases compared to 0.76 in control group ( $\mathrm{p}<0.001)$. (Figure 1) 
Table 1:- patients characteristics.

\begin{tabular}{|c|c|c|c|c|c|}
\hline \multirow[t]{2}{*}{ Variables } & \multicolumn{2}{|c|}{ Cases } & \multicolumn{2}{|c|}{ Control } & \multirow[t]{2}{*}{$\mathbf{P}$} \\
\hline & $\mathbf{n}$ & $\%$ & $\mathbf{n}$ & $\%$ & \\
\hline Age in years (Mean \pm SD) & \multicolumn{2}{|c|}{$48.5 \pm 13.2$} & \multicolumn{2}{|c|}{$44.0 \pm 13.6$} & $0.135^{\#}$ \\
\hline \multicolumn{5}{|l|}{ Sex } & \multirow[b]{3}{*}{0.263} \\
\hline male & 18 & $45.0 \%$ & 23 & $57.5 \%$ & \\
\hline Female & 22 & $55.0 \%$ & 17 & $42.5 \%$ & \\
\hline Hb $($ Mean \pm SD $)$ & \multicolumn{2}{|c|}{$8.1 \pm 2.4$} & \multicolumn{2}{|c|}{$13.7 \pm 1.1$} & $<0.001 *^{\#}$ \\
\hline WBCs (Median; Range) & \multicolumn{2}{|c|}{$20.5(0-411)$} & \multicolumn{2}{|c|}{$7.8(4-10.9)$} & $0.006^{* \$}$ \\
\hline Blasts count & \multicolumn{2}{|c|}{54.026 .2} & \multicolumn{2}{|l|}{-} & - \\
\hline \multicolumn{5}{|l|}{ AML subtypes } & \multirow[t]{8}{*}{-} \\
\hline mo & 4 & $10.0 \%$ & - & - & \\
\hline $\mathrm{m} 1$ & 2 & $5.0 \%$ & - & - & \\
\hline $\mathrm{m} 2$ & 8 & $20.0 \%$ & - & - & \\
\hline $\mathrm{m} 3$ & 8 & $20.0 \%$ & - & - & \\
\hline $\mathrm{m} 4$ & 6 & $15.0 \%$ & - & - & \\
\hline $\mathrm{m} 5$ & 9 & $22.5 \%$ & - & - & \\
\hline $\begin{array}{l}\text { Acute undifferentiated myeloid } \\
\text { leukemia }\end{array}$ & 3 & $7.5 \%$ & - & - & \\
\hline
\end{tabular}

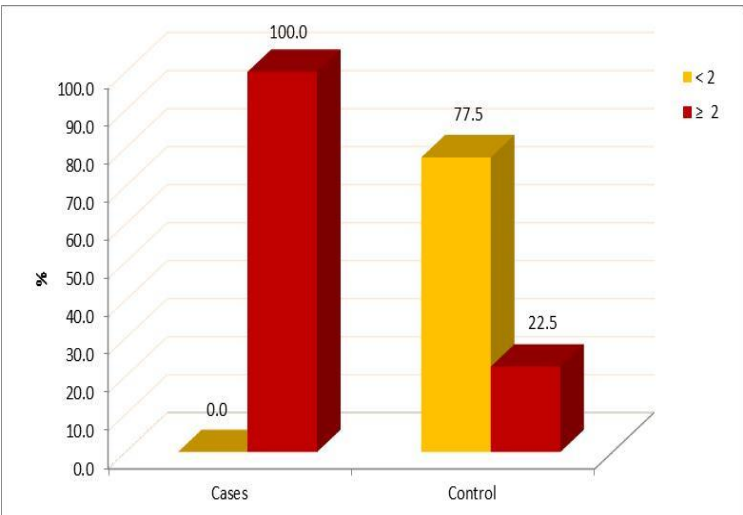

Figure 1:- Comparison between the two studied groups according to AWT1 Expression.

We found no significant correlation between age, sex and expression of AWT1, also we found no correlation between hemoglobin level and gene expression $\left(\mathrm{P}=-0.532 . \mathrm{r}_{=}-0.11\right)$, while there was a positive correlation between white blood cells count and blast count and AWT1 expression $(\mathrm{p}=0.10,0.001)(\mathrm{r}=0.40,0.060)$ respectively.

Also, we found a positive correlation between AML subtypes and AWT1 expression where AWT1 was highly expressed in M3 followed by M4 (74.7\% and 68.9\% respectively).

Table 2:- AWT1 expression in different AML subtypes.

\begin{tabular}{|c|c|c|c|c|c|c|}
\hline \multirow{3}{*}{ AML subtypes } & \multicolumn{4}{|c|}{ AWT1.Expression_C } & \multirow{3}{*}{ Range } & \multirow{3}{*}{ Median } \\
\hline & \multicolumn{2}{|l|}{$<2$} & \multicolumn{2}{|c|}{$>=2$} & & \\
\hline & No & $\%$ & No & $\%$ & & \\
\hline mo & 0 & $0.0 \%$ & 4 & $100.0 \%$ & $3.2-11.6$ & 6.9 \\
\hline $\mathrm{m} 1$ & 0 & $0.0 \%$ & 2 & $100.0 \%$ & $2.0-2.0$ & 2.0 \\
\hline $\mathrm{m} 2$ & 0 & $0.0 \%$ & 8 & $100.0 \%$ & $2.1-13.0$ & 6.1 \\
\hline m3 & 0 & $0.0 \%$ & 8 & $100.0 \%$ & $3.7-14.0$ & 8.1 \\
\hline $\mathrm{m} 4$ & 0 & $0.0 \%$ & 6 & $100.0 \%$ & $9.5-21.1$ & 13.3 \\
\hline & 0 & $0.0 \%$ & 9 & $100.0 \%$ & $2.1-7.5$ & 3.7 \\
\hline Undifferentiated AML & 0 & $0.0 \%$ & 3 & $100.0 \%$ & $2.6-2.7$ & 2.6 \\
\hline Test (P) & \multicolumn{4}{|l|}{-} & \multicolumn{2}{|c|}{$36.7(0.001)^{*}$} \\
\hline
\end{tabular}




\section{Discussion:-}

Wilms' tumor gene 1 (WT1) is gaining increasing attention as a therapeutic target molecule due to its common expression in acute leukemias and its involvement in cell proliferation. ${ }^{(13)}$

AWT1 maintains WT1 exonic structure between exons 2 and 10, but deploys a new 5' exon located in intron 1 of WT1. The AWT1 gene predicts proteins of approximately 32kDa, comprising all exon 5 and exon 9 splicing variants previously characterized for WT1. ${ }^{(14)}$

While we found the levels of WT1 expression were significantly different between different AML subtypes $(\mathrm{P}=0.001)$, Bergmann et al ${ }^{(15)}$ found no relationship concerning the FAB subtype of AML and WT1 expression except in M5 AMLs, which expressed WT1 mRNA in only lower percent of the patients versus in all other de novo AML. This difference may be due to different samples characteristics as we used De novo cases only while they used de novo, MDS related and relapsed cases.

Our study revealed that the AWT1 gene was found to be significantly overexpressed in AML patients relative to control group as AWT1 was overexpressed in $100 \%$ of our patients compared to $22 \%$ of controls $(\mathrm{P}<0.001)$.

Our results are consistent with the findings of Guillaumet-Adkins et al. ${ }^{(16)}$ who used qRT-PCR on a wide range of leukemia and lymphoma cell lines to evaluate the transcription levels of the WT1, AWT1 and the non-coding antisense transcript WT1-AS. In all myeloid origin cell lines evaluated the $W T 1$ and $A W T 1$ transcripts were readily detectable, with high correlation, indicating that they are likely to be co-regulated. The WT1-AS transcript was also expressed in most of the myeloid cell lines. In contrast, the majority of B, T cell leukemic cell lines and lymphomas did not express these transcripts. Moreover, western blotting using an antibody directed against the C-terminal of the WT1 protein revealed that the abundant RNA levels for WT1 and AWT1 isoforms are translated into nuclear retained proteins in the myeloid derived cell lines, consistent with their transcription factor function.

The same results were reported by Furuhata et al. ${ }^{(17)}$ who illustrates the relative mRNA levels of WT1 from 23 AML and 3 ALL patient bone marrows. Most leukemia patients (85\%) showed WT1 mRNA levels of more than $10^{\wedge} 2$ of GAPDH mRNA, whereas the absence of WT1 mRNA was observed only in one AML patient. Additionally, they studied the WT1 mRNA levels in both normal human hematopoietic stem cell fractions (CD34+, CD38-) and progenitor cell fractions (CD34+, CD38+). WT1 mRNA levels of normal stem cell and progenitor cell fractions were significantly lower than those of AML samples with high WT1 mRNA.

In Bergmann et al ${ }^{(15)}$ study mRNA expression was found in in $77 \%$ of all 161 studied samples. The frequency of WT1 expression between de novo AML and AML with antecedent MDS did not differ. Only in patients in first relapse a slightly higher incidence of WT1 mRNA $(87.5 \% \mathrm{v} 74.6 \%)$ was found.

Moreover, the Overexpression of WT1 in AML have been made by studies in human leukemia cell lines and murine models. Notably, downregulation of WT1 expression in primary AML and CML cases (chronic phase and blast crisis) resulted in inhibition of cell growth.In order to further define the role of WT1 overexpression in leukemogenesis, a transgenic murine model of WT1 overexpression in the hematopoietic system was established and bone marrow from transgenic mice overexpressing WT1 was transduced. By contrast, it led to rapid onset leukemia, with a median time to leukemia development of 50 days. ${ }^{(18)}$

These results were supported by the results of Yang et al. ${ }^{(19)}$ When the levels of WT1 expression levels were studied using microarray in AML patients the majority of patients have high levels of WT1. However, some subgroups, have low to absent levels of WT1. In these patients, high levels of WT1 expression may not be well tolerated. This possibility is supported by the growth inhibiting effect of WT1. For example, when the WT1 KTS(+) isoform is expressed in a WT1-negative human myeloblastic leukemic cell line, M1, decreased tumor formation is observed when the cells are injected into immunocompromised mice. This is consistent with a tumor suppressor function of WT1 in some forms of AML.

Interestingly, a study was carried out to determine the prognostic relevance of WT1 gene expression levels in both $\mathrm{BM}$ and PB samples with regard to overall survival (OS) and freedom from relapse (FFR) during follow up. They analyzed the effects of $\mathrm{a} \geq 1-\log$ reduction and $\mathrm{a} \geq 2-\log$ reduction in WT1 mRNA expression. They found that the achievement of $\geq 1-\log$ reduction in BM, WT1 was associated with improved OS and FFR. ${ }^{(20)}$ 
Despite the limited number of patients in this study, their observations were consistent with previous studies, which showed that early MRD measurements could provide predictive information on patient outcome.

AWT1 expression analysis is a promising markers for diagnosis and MRD assessment in AML but larger patient numbers and more studies would be necessary to confirm these data.

\section{References:-}

1. Vardiman JW, Matutes E, Arber DA, Le Beau MM, Porwit A, Tefferi A, et al. (eds). WHO Classification of Tumours of Haematopoietic and Lymphoid Tissues. 4th ed. Lyon: IARC; 2008. 127-9.

2. Burnett AK, Hills RK, Milligan DW, Goldstone AH, Prentice AG, McMullin MF, et al. Attempts to optimize induction and consolidation treatment in acute myeloid leukemia: results of the MRC AML12 trial. J ClinOncol 2010;28:586-95.

3. Riva L, Luzi L, Pelicci PG. Genomics of acute myeloid leukemia: the next generation. Oncology 2012;2:40.

4. Ibrahim AS, Khaled HM, Mikhail NN, Baraka H, Kamel H. Cancer Incidence in Egypt: Results of the National Population-Based Cancer Registry Program. J Cancer Epidemiol 2014;2014:18.

5. Baird PN, Simmons PJ. Expression of the Wilms' tumor gene (WT1) in normal hemopoiesis. ExpHematol 1997; 25:312-20.

6. Mitsuya K, Sui H, Meguro M, Kugoh H, Jinno Y, Niikawa N, et al. Paternal expression of WT1 in human fibroblasts and lymphocytes. Hum Mol Genet 1997; 6:2243-6.

7. Dallosso AR, Hancock AL, Malik S, Salpekar A, King-Underwood L, Pritchard-Jones K, et al. Alternately spliced WT1 antisense transcripts interact with WT1 sense RNA and show epigenetic and splicing defects in cancer. RNA 2007; 13:2287-99.

8. Hohenstein P, Hastie ND. The many facets of the Wilms' tumour gene, WT1. Hum Mol Genet 2006; 15: R196201

9. Li X, Wang S, Sitaram RT, Andersson C, Ljungberg B, Li A. Single nucleotide polymorphisms in the Wilms' tumour gene 1 in clear cell renal cell carcinoma. PLoS One 2013;8(3):58396.

10. Li X, Ottosson S, Wang S, Jernberg E, Boldrup L, Gu X, Nylander K, LiA. Wilms' tumor gene 1 regulates p63 and promotes cell proliferation in head and neck squamous cell carcinoma. BMC Cancer. 2015 May 1; 15(1):342

11. Lim CK, Goh YT, Hwang WY, Ho LP, Sun L. Studies of Wilms' Tumor (WT1) Gene Expression in Adult Acute Leukemias in Singapore. Biomark Insights 2007; 2: 293-8.

12. Boublikova L, Kalinova M, Ryan J, Quinn F, O’Marcaigh A, Smith O, Browne P, Stary J, McCann SR, Trka J, Lawler M. Wilms' tumor gene 1 (WT1) expression in childhood acute lymphoblastic leukemia: a wide range of WT1 expression levels, its impact on prognosis and minimal residual disease monitoring. Leukemia. 2006;20(2):254-63

13. Busse A, Gökbuget N, Siehl JM, Hoelzer D, Schwartz S, Rietz A, et al.Wilms' tumor gene 1 (WT1) expression in subtypes of acute lymphoblastic leukemia (ALL) of adults and impact on clinical outcome. Ann Hematol 2009;88(12):1199-205

14. Dallosso AR, Hancock AL, Brown KW, Williams AC, Jackson S, Malik K. Genomic imprinting at the WT1 gene involves a novel coding transcript (AWT1) that shows deregulation in Wilms' tumours. Hum Mol Genet 2004;13: 405-15.

15. Bergmann L, Miething C, Maurer U, Brieger J, Karakas T, Weidmann E, et al.High levels of Wilms' tumor gene (wt1) mRNA in acute myeloid leukemias are associated with a worse long-term outcome.Blood 1997;90(3):1217-25.

16. Guillaumet-Adkins A, Richter J, Odero MD, Sandoval J, Agirre X, Catala A, et al.,Hypermethylation of the alternative AWT1 promoter in hematological malignancies is a highly specific marker for acute myeloid leukemias despite high expression levels.J HematolOncol 2014;7:4.

17. Furuhata A, Murakami M, Ito H, Gao S, Yoshida K, Sobue S, et al. GATA-1 and GATA-2 binding to 3' enhancer of WT1 gene is essential for its transcription in acute leukemia and solid tumor cell lines.Leukemia 2009;23(7):1270-7

18. Rampal R, Figueroa ME.Wilms tumor 1 mutations in the pathogenesis of acute myeloid leukemia. Haematologica 2016;101(6):672-9.

19. Yang L, Han Y, Suarez Saiz F, Minden MD. A tumor suppressor and oncogene: the WT1 story. Leukemia 2007;21:868-76.

20. Andersson C, Li X, Lorenz F, Golovleva I, Wahlin A, Li A. Reduction in WT1 gene expression during early treatment predicts the outcome in patients with acute myeloid leukemia. DiagnMolPathol 2012; 21(4):225-33. 